of calcium oxalate, was found to be associated with the maintainence of a high blood-calcium. This explains why such crystals are seen only when the naphthalene is administered in connection with oats and cabbage diet.

IV. The relation of these results to the general problem of the rôle of calcium in cataract formation is discussed.

We wish to express our thanks to the Committee on the Physiology of Vision of the Medical Research Council for a grant held by one of us (M. C. B.), and to Professor Drummond for his advice and helpful criticism.

\title{
BIBLIOGRAPHY
}

Adams.-Biochem. Jl., Vol. XXIII, p. 902, 1929.

Brit. Jl. of Ophthal., Vol. XIV, pp. 49 and $545,1930$.

Bourne and Campbell.-Biochem: Jl., Vol. XXVI, p. 183, 1932.

Burge.-A rch of Ophthal., Vol. XXXVIII, p. 447, 1909.

Clark and Collip.-Jl. Biol. Chem., Vol. LXIII, p. 461, 1925.

Cole.-Lancet, Vol. I, p. 13, 1930.

Erdheim.-Mitteil. a. d. Grenzgeb. d. Med. u. Chir., Vol. XVI, p. 632, 1906.

Eisman and Luckhardt.-Proc. Soc. Biol. Med., Vol. XXV, p. 6, 1927.

Graefe-Siameisch Handbuch der Augenhzilk., II Teil., Path. u. Ther. des Linsensyst. Julius Springer, 1911.

Hunter.-Lancet, Vol. I, p. 903, 1930.

Kirby.-A rch. of Ophthal., Vol. V, p. 868, 1931.

Luckhardt and Blumenstock.-Amer. Jl. of Physiol., Vol. LXIII, p. 409, 1923.

Mackay, Stewart and Roberison.-Brit. Jl. of Ophthal., Vol. XVI, p. 193, 1932.

McCrudden.-Jl. Biol. Chem., Vol. X, p. 187, 1911.

O'Brien.-A rch. of Ophthal., Vol. VII, p. 71, 1932.

Peters and Van Slyke.-Quantitative Clinical Chemistry, p. 816. Bàllière, Tindall \& Cox, London, 1931.

\section{RETROBULBAR INJECTIONS AND SEVENTH NERVE BLOCK}

BY

\author{
K. Koman NAYAR, D.O.M.S. \\ AND \\ G. J. Narayanaswamy Nayudu \\ GOVERNMENT OPHTHALMIC HOSPITAL, MADRAS
}

IN the March, 1932, number of the Brit. Jl. of Ophthal., on p. 166, under the heading "Iris anaesthesia by retrobulbar injection and paralysis of the orbicularis oculi by seventh nerve block," Dr. L. Ko Somerville Large has given a detailed description of the technique of, and the complications resulting from the above injections as practised at the Moorfields Hospital during his period of residency there. 
In this connection we think it may interest your readers to know our experience regarding these injections as practised in this clinic for a number of years. Prior to the publication of his method of seventh nerve block by O'Brien in the Arch. of Ophthal., for December, 1929, we followed the method introduced by Lt.-Col. R. E. Wright, I.M.S., the Superintendent of this Hospital, of blocking the seventh nerve, near the stylomastoid foramen at its exit from the cranial cavity by an injection of 1 c.c. of a 2 per cent. novocaine solution combined with 1 or 2 drops adrenalin solution (1 in 1,000). (This method has been published in the Arch, of Ophthal., Vol. LV. p. 555, 1926.) Although this gave us good results, we had no hesitation in giving it up in favour of O'Brien's method, early in 1930, as we found the latter easier, more certain and safer. Dr. Somerville Large also followed the method advocated by O'Brien and is satisfied with his results.

The technique of retrobulbar injections for the production of iris anaesthesia, as practised here for over four years, is almost the same as that described by Dr. Somerville Large. At first we adopted it only in cases for iridectomy in painful or glaucomatous eyes, for sclero-corneal trephinings and for intracapsular extraction of cataract done by Barraquer's method; but for the last $2 \frac{1}{2}$ years we have been giving it, as a regular routine, in all intra-ocular operations in which iris anaesthesia is desirable. In this clinic over 5,000 cases have received the retrobulbar injection and the seventh nerve block during the last few years, so that we are enabled to form a definite opinion of the usefulness of these injections and the complications resulting therefrom.

Instead of the 2 c.c. hypodermic syringe with a $1 \frac{1}{4}$ in. needle used by Dr. Somerville Large, we have been using a dental syringe with fine "Alston" hypodermic needles, about $40 \mathrm{~mm}$. long. The syringe is a $60 \mathrm{~mm}$. one and our usual practice is to take up a syringeful of a 4 per cent. novocaine solution to which a few drops of adrenalin have been added and use first about 1 c.c. for the retrobulbar injection and then 1 to 1.5 c.c. of the remaining solution for the seventh nerve block. Ten cases are usually done at a time; we have found this a most convenient and quick method in our routine work of dealing with 20 to 30 cases on an operation morning. When we started the retrobulbar injections, we were using needles $60 \mathrm{~mm}$. long and rather coarse (pushing in the needle only to a depth of $1 \frac{1}{4}$ or $1 \frac{1}{2}$ in.). This gave us more cases of retrobulbar haemorrhage than when later we began to use the $40 \mathrm{~mm}$. fine thin needles.

At present we get orbital haemorrhages very, very rarelyprobably less than 0.5 per cent., even in the hands of begirners. Dr. Somerville Large's four cases of orbital haemorrhage in a total of 84 were all in acutely inflamed eyes with high tension. We observed this occasional complication for the most part in the 
ordinary cases of cataract extraction, and not in congested or inflamed eyes.

As regards the second complication referred to by Dr. Somerville Large, i.e., paralysis or paresis of the inferior rectus, we have frequently had the same experience in spite of trying to keep away from the inferior rectus muscle or the floor of the orbit as much as possible. This complication is especially annoying, when, in a cataract operation, where the section is made above, one is trying to deliver the lens or do a peripheral iridectomy with the eye turned strongly upwards. It may be that the injected solution has the natural tendency to gravitate to the lower part of the orbit and thus affect the inferior rectus most often. We do occasionally get paralysis of the other muscles also, and sometimes all the recti muscles, which latter condition is of great help to the operator especially in cases of intracapsular cataract extraction with the Erisiphake. Paralysis of the inferior rectus alone will probably be avoided if one keeps the needle towards the lateral part of the orbit and tilts it slightly upwards just before injecting the fluid, or by making the patient look down at this stage.

As regards the local anaesthesia required for cases of excision of the eyeball, we are in entire agreement with Dr. Somerville Large, but for cases of evisceration, we are of opinion that only one retrobulbar injection with superficial conjunctival anaesthesia by cocaine drops is all that is necessary.

In this connection, it may not be out of place to refer to a point raised in p. 158 of the same copy of your journal by Dr. R. C. J. Meyer in his article on "The intracapsular extraction of cataract," regarding the importance of limiting the quantity of the fluid used in these retrobulbar injections. He limits it to 8 minims of a 2 per cent, solution and is of opinion that a larger quantity is liable to produce vomiting which may be followed by expulsive haemorrhage. He had four such cases out of a total of 64. He has not made it clear as to what actually causes the vomiting, whether a reflex action due to pressure on the nerves in the orbit or the absorption of a poisonous dose of novocaine into the general system. Our average dose is 1 c.c. of the 4 per cent. stock solution of novocaine (mixed with a drop or two of adrenalin), but in cases of excision of the eyeball, we have injected into the orbit as much. as 4 to 6 c.c. of a 2 per cent. solution. In our experience we have not had any vomiting after a retrobulbar novocaine injection, though given in much larger quantities than the maximum adopted by Dr. Meyer. 